Jihen Maatoug, Sihem Ben Fredj*, Zeineb Msakni, Emna Dendana, Jihene Sahli, Imed Harrabi, Firas Chouikha, Lamia Boughamoura, Slim Slama, Nathalie Farpour-Lambert and Hassen Ghannem

\title{
Challenges and results of a school-based intervention to manage excess weight among school children in Tunisia 2012-2014
}

DOI 10.1515/ijamh-2015-0035

Received April 22, 2015; accepted July 2, 2015; previously published online September 11, 2015

\section{Abstract}

Background: Obesity is a serious health issue and predisposes individuals to an increased risk of morbidity and mortality. Its prevalence in children has increased worldwide.

Objective: To demonstrate the feasibility and effectiveness of a school-based management program based on healthy lifestyle promotion for obese and overweight adolescents in Sousse, Tunisia.

Methods: We conducted a quasi-experimental study among overweight and obese school children enrolled in 7th and 8th grades in Sousse, Tunisia with two groups, intervention and control. The 1-year intervention was based on promoting healthy eating and physical activity through a collective intervention for all recruited children and an individual intervention only for obese children who require intensive managing. Data collection was done before, at the end and at a 4-month follow up of the intervention, both in intervention and control groups.

Results: The body mass index $\mathrm{Z}$ score decreased significantly from pre-intervention to post-intervention (1.89 \pm 0.57 to $1.76 \pm 0.63, \mathrm{p}<0.001)$ and from post-intervention to the

\footnotetext{
*Corresponding author: Sihem Ben Fredj, Department of Epidemiology, University Hospital Farhat Hached, Sousse, Tunisia, E-mail: sihem-benfredj@hotmail.com

Jihen Maatoug, Zeineb Msakni, Emna Dendana, Jihene Sahli, Imed Harrabi, Firas Chouikha and Hassen Ghannem: Department of Epidemiology, University Hospital Farhat Hached, Sousse, Tunisia Lamia Boughamoura: Pediatric Department, University Hospital Farhat Hached, Sousse, Tunisia

Slim Slama: Department of Community Medicine, Primary Care and Emergency, University Hospitals of Geneva, Geneva, Switzerland Nathalie Farpour-Lambert: Department of Child and Adolescent, University Hospitals of Geneva, Geneva, Switzerland
}

follow-up (1.76 \pm 0.63 to $1.55 \pm 0.68, \mathrm{p}<0.001)$ in the intervention group. In the control group, it decreased significantly from pre-intervention to post-intervention but not significantly from post-intervention to follow-up assessment. Calorie intake decreased significantly both in intervention and control groups.

Conclusion: This project began with introducing a new culture of health management in schools on one side and with increasing awareness of the importance of obesity prevention and treatment. The support of authorities for this type of action is very important to guarantee its sustainability.

Keywords: adolescent; intervention; obesity; schools.

\section{Introduction}

Obesity is a serious health issue that predisposes individuals to an increased risk of morbidity and mortality from conditions such as Type 2 Diabetes Mellitus (T2DM) $(1,2)$. In many countries, the problem of childhood obesity in particular is increasing at a dramatic rate $(3,4)$. Surveys during the 1990s show that in Brazil and the USA, an additional $0.5 \%$ of the entire child population became overweight each year. In Canada, Australia and parts of Europe the rates were higher, with an additional 1\% of all children becoming overweight each year (5). Tunisia is also concerned with this problem $(6,7)$. In 2005 , the prevalence of overweight and obesity among adolescents was estimated at $20.1 \%$ and $5.0 \%$, respectively (6).

The treatment of obese youth is a costly and challenging endeavor and prevention strategies are clearly warranted $(8,9)$. There is evidence of modest short-term success with behavioral therapies combining nutritional education and physical activity components (10, 11). However, the rising rate of obesity in children indicates a strong need for translational research that assesses intervention and programs in communities. 
Utilizing existing community resources is one way to begin implementing these types of programs. For example, schools provide ready access to children in the community and have numerous advantages for promoting healthy lifestyle modifications, including regular parent and child contact and availability of health-promoting resources such as health education and physical activity classes $(12,13)$. Despite these assets, there is limited evidence for the effectiveness of weight management programs that take place in the school setting $(14,15)$.

Targeted interventions can involve multiple components, but are directed at specific individuals or groups of individuals. Although the whole-of-school approach has the potential to have a positive impact on the health behaviors of a large number of students, this type of intervention may be less effective among those most in need, such as overweight and obese students (16).

Lifestyle interventions for the treatment of pediatric excess weight are effective in the short-term with some evidence for persistence of effects (17). Also, family-based behavioral therapy is a promising approach (18). It provides simultaneous treatment for the overweight parent and child to modify the family environment and to provide role models and support for child behavior changes (19). In fact, families are able to construct children's lifestyle habits, through their parenting style and management of family functioning (19).

However, this requires group leaders and multiple counselors to meet with families (20). As a matter of fact, the "Contrepoids" program of the Geneva University Hospital in Switzerland is based on two principles: treating the obese child involves the entire family and treatment is based on a healthy lifestyle, not a restricted diet $(21,22)$. In this study, we propose to adapt this program in partnership with the Geneva University Hospital to manage overweight and obesity in schools among children in the region of Sousse, Tunisia.

Our objective was to demonstrate the feasibility and effectiveness of a school-based weight management program based on healthy lifestyle promotion for obese and overweight adolescents in Sousse, Tunisia.

\section{Materials and methods}

\section{Study design}

We conducted a quasi-experimental study to investigate the effectiveness of a school-based intervention to change lifestyle habits and consequently reduce the body mass index (BMI) in obese and overweight children in Sousse, Tunisia from 2012 to 2014. The intervention group included four schools in the jurisdiction of Sousse Jawhara and Sousse Erriadh and the control group included two schools in the jurisdiction of Msaken.

\section{Study population}

Sample size: Sample size estimates were based on a two-sided significance level of 0.05 and $80 \%$ power to detect a 0.15 difference of BMI Z-score after a 1-year intervention. Assuming a failure to consent rate of $10 \%$ (not eligible as well as declining to participate) and a dropout rate of $10 \%, 250$ participants in each group were needed. All overweight and obese school children enrolled in the 7th and 8th grades in the selected colleges were invited to participate in the study.

\section{Measures}

Body weight was recorded to the nearest $0.1 \mathrm{~kg}$ using a portable electronic scale. Standing height was measured with the participants in their bare feet to the nearest $0.5 \mathrm{~cm}$ using a portable stadiometer fixed on the wall.

Overweight and obesity: BMI was calculated as weight $(\mathrm{kg}) /$ height $^{2}$ $\left(\mathrm{m}^{2}\right)$ and Z-scores were derived using the World Health Organization references (23). Overweight was defined as a BMI between 1 and 1.99 SD and obesity was above $2 \mathrm{SD}$.

\section{Intervention program}

The "Contrepoids" program conducted in Switzerland consisted of children who consulted for help on their own to lose weight. It included a multidisciplinary team with a pediatrician, dietician, physical activity teacher and psychologist. In our program, we used the same strategy of intervention with similar actors. However, in our case, children were encouraged to participate and lose weight in schools after screening.

Concerning tools used in the "Contrepoids" program, they were translated in Arabic using examples of meals and foods from our context. During the 1-year intervention, recruited school children were managed for excess weight. There were two intervention strategies: A collective intervention for all recruited children (overweight and obese) and an individual intervention only for obese children who required intensive managing.

Collective intervention: The intervention group included collective sessions with groups of around 15 school children. These sessions lasted $1 \mathrm{~h}$, and we distributed to participants a document including interactive exercises to do during the sessions and others to do individually. We organized three types of interventions in each college.

- Collective sessions for overweight and obese children organized in schools about healthy eating. These sessions were conducted by a dietician recruited for the project with the participation of nurses.

- The second type of session was presented by a psychologist in the schools to improve self esteem among overweight and obese children. 
- $\quad$ The third collective session was presented by a medical doctor and was about snacking for overweight and obese children.

Teachers also proposed a program of twice a week physical activity sessions in schools for overweight and obese school children (independently from the physical activity school sessions). This physical activity program was adapted to the capacity and preferences of participants.

Individual intervention: In the beginning of the program, we called school children with their parents to a consultation with a medical doctor from the project team to announce the diagnosis of overweight or obesity of children and to explain the risk of this status and to propose involvement in the project program. Those who freely consented (signed informed consent), responded to a 24-h food and physical activity recall questionnaire and participated in biomedical measures of body weight and body height.

The first meeting considered all overweight and obese children recruited in the study. The main objective of this consultation was to give advice about healthy eating habits and the importance of doing regular physical activity. Then, only obese children were invited to a consultation every 3 months. There was an individual consultation witha psychologist to assess psychological status (screening for depression or low self esteem level) and provide psychological support for obese participants in the intervention group.

Another individual consultation was with a dietician who proposed personalized healthy diets for each obese participant according to his/her eating habits and BMI.

The pediatrician also offered a consultation for screening of causes of obesity such as hypothyroidism and/or complications. He also educated and motivated participants to follow a healthy diet and participate in regular physical activity.

In this project, we trained physical activity teachers and school medical doctors; we also sensitized school staff and parents to the importance of healthy habits and obesity management. We gave sports equipment to the schools to help improve physical activity sessions. In addition, all obese children were referred to a general practitioner or pediatrician for the continuity of obesity management.

\section{Data collection}

Data was collected before the intervention, at the end of the intervention and at the 4-month follow up (after the end of the intervention), both in the intervention and control groups. Data collection was composed of a 24-h food and physical activity recall.

For the 24-h food recall, participants filled out a table that requests time of each meal, composition and quantity during 3 days (including weekends). After that, the completed questionnaire is discussed with the dietician if more details are required to be able to calculate caloric intakes.

A physical activity recall was also filled out for 3 days using a table that included activities done at 30-min intervals from the time the participant wakes up to when they go to sleep. Each activity was described as either light, moderate, hard or very hard.

Conversion to kcal/day: Time spent in sleep (1 MET), light (1.5 METs), moderate (4 METs), hard (6 METs) and very hard (10 METs) activities for the previous 3 days were multiplied by their respective MET values and then summed. An estimate of total kilocalories of energy expenditure per day is the mean of the 3 days (24). We also took biomedical measures (body weight, body high).

\section{Statistical analyses}

We used SPSS, version 10.0 software (SPSS Inc., Chicago, USA) for data capture and analysis. A probability of $<0.05$ was considered statistically significant for all tests. We used a paired sample t-test to compare means at pre- and post-assessment in each group.

\section{Procedures}

Data collectors were trained by project coordinators on the different questionnaires used. There was a presentation of tools, instructions to follow for each questionnaire and simulation of interviews. The same training was done for anthropometric measures. Dieticians were also trained by an experimented dietician to standardize data collection. Interventionists were trained by “Contrepoid's" program team composed of a dietician, pediatrician, physical activity teacher and psychologist over 3 days to standardize intervention messages for the precise aims of each consultation and collective session according to "Contrepoid's" program.

The protocol was approved by the Ethical Committee of the University Hospital Farhat Hached.

We screened for excess weight among all school children in the 7th and 8th grades in selected schools. All children who presented characteristics of overweight or obesity were contacted with their parents to receive a diagnosis and invitation for participation in the study.

We obtained children's free assent and parent's free, informed consent before their participation in the study. In the control area, all screened obese and overweight school children were referred to the school medical doctor for biomedical measures for potential management. We offered a delayed intervention to the control group after the end of the project.

\section{Results}

The intervention group was composed of 317, 225 and 171 school children, respectively, at pre-assessment, postassessment and 4-month follow up. The control group was composed of 268, 180 and143 school children (Figure 1). The main reasons of attrition was unavailability of students because of busy schedule or change of schools. The mean of BMI Z-score of drop out participants was $1.85 \pm 0.55$ vs. $1.89 \pm 0.57$ among those who were present at the third measure (at 4-month follow up) in the intervention group $(\mathrm{p}=0.61)$.

In the control group, the mean of BMI Z-score among drop out participants was $1.77 \pm 0.60$ vs. $1.89 \pm 0.63$ among 


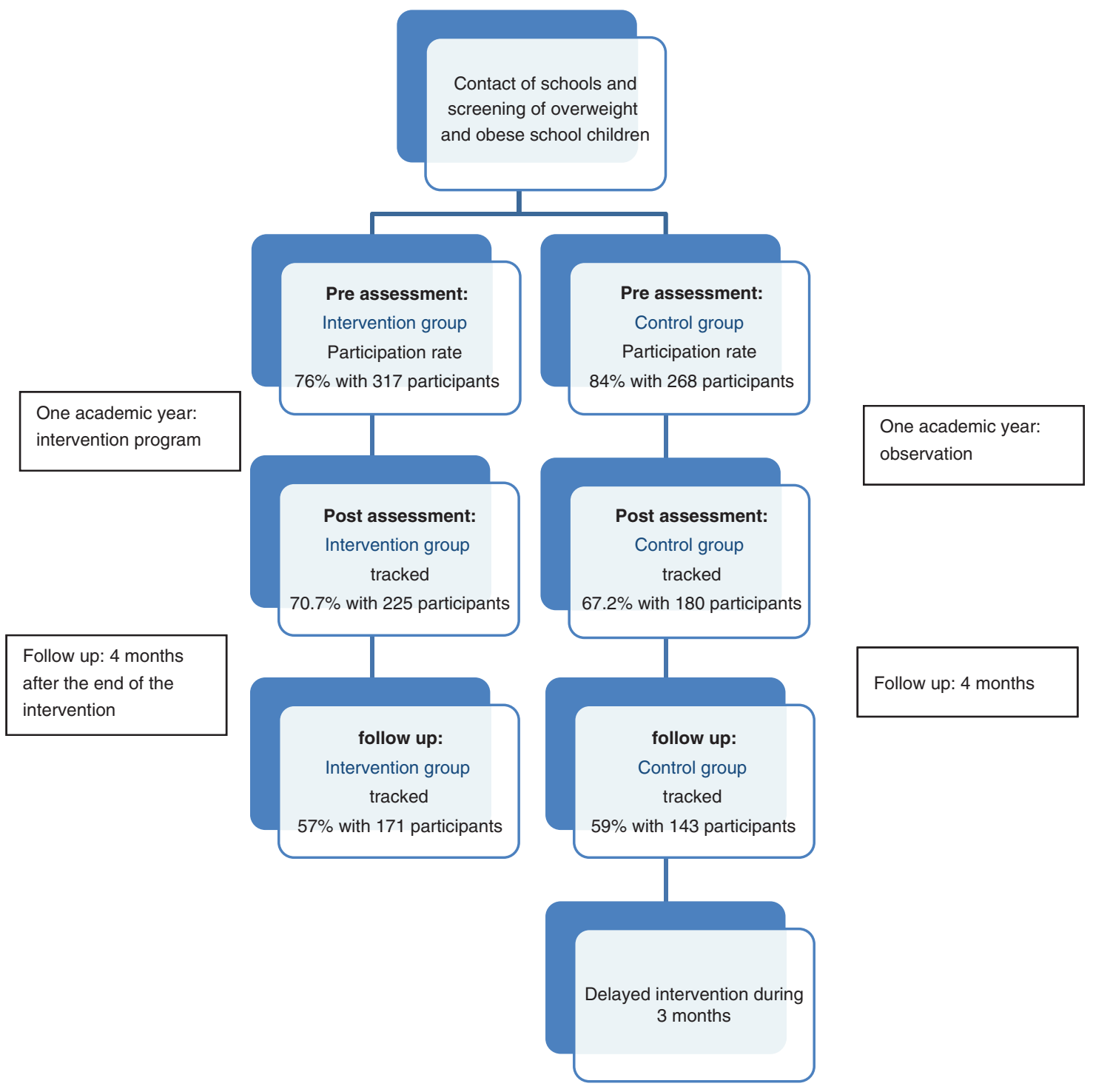

Figure 1: Participation rate of school children in intervention study to manage excess weight in Sousse, Tunisia. Design: quasi-experimental.

those who were present at follow up $(\mathrm{p}=0.12)$. The mean age of participants was respectively $13.1 \pm 0.96$ and $13.5 \pm 0.89$ years in the intervention and control groups. The proportion of girls was $56.7 \%$ and $63.6 \%$ in the intervention and control groups.

The mean BMI was 25.5 \pm 3.4 in the intervention group, with $50.3 \%$ overweight. It was $26.1 \pm 3.9$ in control group with $55.9 \%$ overweight (Table 1). Overweight represented $45.9 \%$ among boys and $53.6 \%$ among girls $(\mathrm{p}=0.31)$ in the intervention group. In the control group, it represented $51.9 \%$ among boys and $58.2 \%$ among girls $(\mathrm{p}=0.48)$.

The body mass index Z-score decreased significantly from pre-intervention to post-intervention and from postintervention to the follow up 4 months after the end of the intervention in the intervention group. In the control group, it decreased significantly from pre-intervention to post-intervention but not significantly from post-intervention to follow up assessment (Table 2).

Table 1: Characteristics of participants in intervention and control groups at pre-assessment.

Intervention group Control group

\begin{tabular}{lrr}
\hline Age Mean, SD & $13.1(0.9)$ & $13.5(0.9)$ \\
Proportion of girls, n, \% & $179(56.7)$ & $170(63.6)$ \\
Proportion of overweight, n, \% & $159(50.3)$ & $149(55.9)$ \\
Body mass index, mean, SD & $25.5(3.4)$ & $26.1(3.9)$ \\
\hline
\end{tabular}


The BMI increased significantly from pre-intervention to post-intervention and decreased significantly from postintervention to the follow up four months after the end of the intervention in the intervention group. In the control group, BMI increased significantly from pre-intervention to the follow up assessment $(\mathrm{p}=0.004)$. Tables 3 and 4 showed that caloric intake decreased significantly both in the intervention and control groups. However, physical activity expenditure increased significantly only in the control group from pre- to post-assessment.

In the intervention group, $69.7 \%$ of participants said that they wanted to lose weight. The reasons that limited the participation of school children in the activities of the intervention program were mainly due to their busy schedule in school with $27.1 \%$. The other reasons were that school children were afraid of being mocked by their friends in $13.1 \%$ of the cases, that the content of the program didn't catch their attention in $11.3 \%$, that they didn't think they needed to lose weight in $6.8 \%$ and that their family didn't encourage them in $4.1 \%$ of cases.

Most of the participants found the activities offered by the program interesting, particularly when it concerned diet. However, the participation rate was less important in regards to the collective sessions and physical activity sessions (Table 5). The majority of participants in the intervention group said that they will continue the program by themselves with $89.6 \%$.

Table 2: Evolution of BMI and BMI Z-score in intervention and control groups from pre-intervention to the follow up assessment (4 months after the end of the intervention).

\begin{tabular}{|c|c|c|c|c|c|}
\hline & Pre-assessment mean, SD & Post-assessment mean, SD & Follow up mean, SD & p-Value (pre-post) & p-Value (post-follow up) \\
\hline \multicolumn{6}{|c|}{ Intervention group $(\mathrm{n}=171)$} \\
\hline BMI Z-score & $1.89(0.57)$ & $1.76(0.63)$ & $1.55(0.68)$ & $<0.001$ & $<0.001$ \\
\hline $\mathrm{BMI}, \mathrm{kg} / \mathrm{m}^{2}$ & $26.12(3.91)$ & $26.37(4.17)$ & $26.54(4.21)$ & 0.075 & 0.097 \\
\hline \multicolumn{6}{|c|}{ Control group $(n=143)$} \\
\hline BMI Z-score & $1.89(0.63)$ & $1.71(0.72)$ & $1.69(0.73)$ & $<0.001$ & 0.230 \\
\hline $\mathrm{BMI}, \mathrm{kg} / \mathrm{m}^{2}$ & $25.47(3.46)$ & $25.96(3.67)$ & $25.28(3.64)$ & 0.001 & $<0.001$ \\
\hline
\end{tabular}

Table 3: Evolution of the calorie intake before and after the intervention conducted in the region of Sousse to manage obesity among school children 2012-2014 in intervention group.

\begin{tabular}{lrrrr}
\hline & & & Intervention group \\
\cline { 2 - 5 } & Pre-intervention mean (ET) & Post-intervention mean (ET) & Follow up mean (ET) & p-Value (pre-post) \\
\hline Physical activity & $2752.8(931)$ & $2782.5(672)$ & $2623.5(652)$ & 0.690 \\
expenditure, kcal/day & & & & \\
Calorie intake & $2636.0(698)$ & $2364.8(787)$ & $2414.4(910)$ & $<0.001$ \\
Lipids intake, g & $109.1(39)$ & $94.3(34)$ & $36.0(37)$ & 0.001 \\
Glucids intake, g & $352.7(249)$ & $322.0(116)$ & $316.9(134)$ & 0.040 \\
Proteins intake, g & $76.8(32)$ & $68.3(27)$ & $68.1(18)$ & 0.002 \\
\hline
\end{tabular}

Table 4: Evolution of the calorie intake before and after the intervention conducted in the region of Sousse to manage obesity among school children 2012-2014 in control group.

\begin{tabular}{lrrrr}
\hline & & & Control group \\
\cline { 2 - 5 } & Pre-intervention mean (ET) & Post-intervention mean (ET) & Follow up mean (ET) & p-Value (pre-post) \\
\hline Physical activity & $2486.5(596)$ & $2713.5(795)$ & $2695.2(600)$ & 0.001 \\
expenditure, kcal/day & & & & \\
Calorie intake & $2578.8(592)$ & $2374.2(627)$ & $2101.0(686)$ & $<0.001$ \\
Lipids intake, g & $106.6(36)$ & $96.8(35)$ & $86.6(32)$ & $<0.001$ \\
Glucids intake, g & $334.9(80)$ & $305.1(85)$ & 6.001 \\
Proteins intake, g & $70.3(14)$ & $73.4(44)$ & $62.9(14)$ & 0.3760 \\
\hline
\end{tabular}


Table 5: Attitudes of participants in intervention group toward the program at post-assessment.

\begin{tabular}{|c|c|c|c|}
\hline & It was interesting & I didn’t participate & Other opinions (not interesting or no opinion) \\
\hline Collective sessions about healthy diet & 76.7 & 12.4 & 12.9 \\
\hline Collective sessions about snacks & 65.0 & 21.2 & 13.8 \\
\hline Collective sessions with psychologist & 54.2 & 30.0 & 15.8 \\
\hline Session of physical activity & 56.9 & 28.0 & 25.1 \\
\hline Individual session with dietician & 75.5 & 10.2 & 14.3 \\
\hline Individual session with psychologist & 68.7 & 17.7 & 13.6 \\
\hline Visit to pediatrician & 58.4 & 20.8 & 20.8 \\
\hline
\end{tabular}

\section{Discussion}

To our knowledge, this intervention is the first in Tunisia to offer multi-component interventions in a school setting. We tried to evaluate the effectiveness of this program while also assessing the feasibility, contextual barriers and facilitators observed. BMI Z-score decreased significantly both in the intervention and control groups, but it continued to decrease only in the intervention group. BMI decreased in the intervention group from post-intervention to follow-up measures only.

It should be noted that the significant decrease of BMI and BMI Z-score in the intervention group was seen only after the 4-month follow up. These results could be explained by many hypotheses. One explanation is the known difficulty of behavior change (25). Another is that our intervention consisted of healthy lifestyle promotion and not a restrictive diet to allow the children to adopt these habits long-term and not just for a few weeks or months. For these reasons, a decrease in BMI may take more time so the effect of the intervention might only be found after a longer period of time $(26,27)$. We should therefore extend the duration of the intervention to be more effective and to verify this hypothesis.

We recognize that this intervention didn't show a pronounced decrease of BMI and that a quasi-experimental design couldn't insure the intervention effect. However, healthy lifestyle promotion for obesity control is beneficial for children (28) especially in the context of Tunisia. In fact, the transitional context in our country exposes children to unhealthy eating and limits the choice for healthy products $(29,30)$. In addition our infrastructure is inadequate for practicing physical activity. Even the school environment presents a high risk for obesity, where physical activity is devalued at the expense of school sedentary activities that last $8 \mathrm{~h}$ a day. Children in Tunisia don't have time, equipment or support to adopt healthy lifestyles. Such programs could introduce a new momentum and school life that is not focused only on education but also on promoting children's health. Furthermore, school-based programs can have long-term effects in a large target group, but we shouldn't overlook parents and the family's role in lifestyle choices (31-34). Engaging parents in childhood obesity prevention programs may make weight loss easier for children $(35,36)$.

The project team also observed that overweight participants were not very motivated to lose weight. Unfortunately, we couldn't demonstrate this statement directly. Nevertheless, during the intervention program, we noticed that parents gave a lot of importance to the academic results of their children over losing weight, and they underestimated overweight status. At the beginning of the study, when we discussed with them about the importance of losing weight and consequences of obesity, they seemed to be motivated and engaged to help their children to lose weight. However, when we consider the Tunisian context, where people give a lot of importance to academic results, where the environment supports unhealthy habits and doesn't give enough importance to prevention, we concluded that participants will give up after a certain time. In fact, when we called parents by phone to schedule an appointment with the dietician or a group session for example, sometimes they accepted without any problem but were absent at the appointment and sometimes they apologized under the pretext that their children had examinations and they didn't have time to consult. However, children who are motivated to lose weight because of family/social influences may be more highly engaged in treatment and lose more weight, as compared to children who are less motivated by family and social reasons $(37,38)$.

Therefore, we couldn't affirm with certainly the effectiveness of the program according to the discussed conditions, but it's also not possible to say that it wasn't effective compared to results in the control group. That's why, to be more objective in evaluating this program, we suggest doing it among obese children who request consultations on their own. It is also important to ensure more adequate environments that support and give priority to health promotion (with the implication and support of 
teachers, administrative staff, parents and stakeholders) (37) and lasts over a longer period of time $(26,27)$.

School-based obesity interventions should take into account student interests and involvement, classroom skills of teachers delivering the intervention, teacher/ staff attitudes and engagement concerning intervention delivery, menu and product ordering systems, and buy-in from school leadership (39). Some teachers in our program reported being unable to implement intervention components due to school prioritization of non-healthrelated curricula and standardized testing requirements. A number of barriers related to teachers or food service staff were encountered, including resistance to change, lack of motivation and participation in intervention delivery, lack of compliance in intervention delivery and lack of communication and cooperation among teachers and staff effect intervention implementation (38-41).

Even though schools could represent an ideal site to intervene with children (42, 43), behavior intervention activities may need to be developed or revised with input from youth to maximize developmental appeal and motivation $(39,44)$. Schools may also present a barrier for interventions to promote physical activity because children are required to sit quietly for the majority of the day to receive academic lessons (45). In our intervention, although we gave sports equipment to schools to improve physical activity sessions, physical activity expenditure didn't increase in the intervention group. Policymakers should set higher standards and increase resources not only for health professionals but also for teachers in schools and the environment to improve access to healthy diet and physical activity (39).

The improvement seen both in the intervention and control groups concerning BMI and caloric intake could be due to a Hawthorne effect. In fact, many participants in the control group were already motivated to lose weight and when we collected data among them, they started trying to lose weight by themselves. The project team noted also that they asked to be managed to lose weight. Furthermore, a spontaneous decrease of BMI or BMI Z-score couldn't be possible as mentioned in previous studies (46).

This project began with efforts to introduce a new culture of health management in schools and to increase awareness of the importance of obesity prevention and treatment. However, the support of the authorities of this type of action is very important to guarantee its sustainability.

Acknowledgments: This project is supported by a BRIDGES Grant from the International Diabetes
Federation. BRIDGES, an International Diabetes Federation project, is supported by an educational grant from Lilly Diabetes.

\section{References}

1. Bray GA. Obesity increases risk for diabetes. Int J Obes Relat Metab Disord 1992;16(Suppl 4):S13-7.

2. Reilly J, Methven E, McDowell Z, Hacking B, Alexander D, et al. Health consequences of obesity. Arch Dis Child 2003;88: 748-52.

3. Thibault H, Rolland-Cachera MF. Prevention strategies of childhood obesity. Arch Pediatr 2003;10:1100-8.

4. Lobstein T, Frelut ML. Prevalence of overweight among children in Europe. Obes Rev 2003;4:195-200.

5. Lobstein T, Baur L, Uauy R, IASO International Obesity TaskForce. Obesity in children and young people: a crisis in public health. Obes Rev Off J Int Assoc Study Obes 2004;5(Suppl 1): 4-104.

6. Aounallah-Skhiri H, El Ati J, Traissac P, Ben Romdhane H, Eymard-Duvernay $S$, et al. Blood pressure and associated factors in a North African adolescent population. A national crosssectional study in Tunisia. BMC Public Health 2012;12:98.

7. Harrabi I, Bouaouina M, Maatoug J, Gaha R, Ghannem H. Prevalence of the metabolic syndrome among urban schoolchildren in Sousse, Tunisia. Int J Cardiol 2009;135:130-1.

8. Colagiuri S, Lee CMY, Colagiuri R, Magliano D, Shaw JE, et al. The cost of overweight and obesity in Australia. Med J Aust 2010;192:260-4.

9. Allender S, Rayner M. The burden of overweight and obesity-related ill health in the UK. Obesity Reviews 2007;8:467-73.

10. Nemet D, Barkan S, Epstein Y, Friedland O, Kowen G, et al. Short- and long-term beneficial effects of a combined dietarybehavioral-physical activity intervention for the treatment of childhood obesity. Pediatrics 2005;115:e443-9.

11. Knöpfli BH, Radtke T, Lehmann M, Schatzle B, Eisenblatter J, et al. Effects of a multidisciplinary inpatient intervention on body composition, aerobic fitness, and quality of life in severely obese girls and boys. J Adolesc Health 2008;42:119-27.

12. Pyle SA, Sharkey J, Yetter G, Felix E, Furlong MJ, et al. Fighting an epidemic: the role of schools in reducing childhood obesity. Psychol Sch 2006;43:361-76.

13. Brown T, Summerbell C. Systematic review of school-based interventions that focus on changing dietary intake and physical activity levels to prevent childhood obesity: an update to the obesity guidance produced by the National Institute for Health and Clinical Excellence. Obesity Rev 2009;10:110-41.

14. Summerbell CD, Waters E, Edmunds LD, Kelly S, Brown T, et al. Interventions for preventing obesity in children. Cochrane Database Syst Rev 2005;3:CD001871.

15. Kropski JA, Keckley PH, Jensen GL. School-based obesity prevention programs: an evidence-based review. Obesity (Silver Spring) 2008;16:1009-18.

16. Salmon J, Booth ML, Phongsavan P, Murphy N, Timperio A. Promoting physical activity participation among children and adolescents. Epidemiol Rev 2007, 29:144-59. 
17. Wilfley D, Tibbs T, Van Buren D, Reach K, Walker M, et al. Lifestyle interventions in the treatment of childhood overweight: a meta-analytic review of randomized controlled trials. Health Psychol 2007;26:521-32.

18. Oude Luttikhuis H, Baur L, Jansen H, Shrewsbury VA, O’Malley C, et al. Interventions for treating obesity in children. Cochrane Database Syst Rev 2009;1:CD001872.

19. Baker JL, Farpour-Lambert NJ, Nowicka P, Pietrobelli A, Weiss R. Evaluation of the overweight/obese child--practical tips for the primary health care provider: recommendations from the Childhood Obesity Task Force of the European Association for the Study of Obesity. Obes Facts 2010;3:131-7.

20. Farpour-Lambert N, Nydegger A, Puder J, Kriemler S, L'Allemand D. Comment traiter l'obésité de l'enfant? Importance de la prévention primaire. Rev Med Suisse 2008;4:533-6.

21. Hopitaux universitaires Genève. Contrepoids program. http://contrepoids.hug-ge.ch/informations/obesite_enfants_ados.html.

22. Farpour-Lambert NJ, Aggoun Y, Marchand LM, Martin X, Herrmann F, et al. Physical activity reduces systemic blood pressure and improves early markers of atherosclerosis in pre-pubertal obese children. J Am College Cardiol 2009;54:2396-406.

23. Group. WMGRS: WHO Child Growth Standards: Length/heightfor-age, weight-for-age, weight-for-length, weight-for-height and body mass index-for-age: Methods and development. Organization GWH, 2006:312. Available at: http://www.who.int/ childgrowth/standards/Technical_report.pdf.

24. Sallis JF, Haskell WL, Wood PD, Fortmann SP, Rogers T, et al. Physical activity assessment methodology in the Five-City Project. Am J Epidemiol 1985;121:91-106.

25. Prochaska JO, Diclemente CC. Toward a Comprehensive Model of Change. In: Miller WR, Heather N, editor. Treating Addictive Behaviors. New York: Springer, 1986:3-27.

26. Caballero B, Clay T, Davis SM, Ethelbah B, Rock BH, et al. Pathways: a school-based, randomized controlled trial for the prevention of obesity in American Indian schoolchildren. Am J Clin Nutr 2003;78:1030-8.

27. McGovern L, Johnson JN, Paulo R, Hettinger A, Singhal V, et al. Treatment of pediatric obesity: a systematic review and meta-analysis of randomized trials. J Clin Endocrinol Metab 2008;93:4600-5.

28. Oude Luttikhuis H, Baur L, Jansen H, Shrewsbury VA, O'Malley C, et al. Interventions for treating obesity in children. Cochrane Database of Systematic Reviews. John Wiley \& Sons, Ltd, 1996.

29. Aounallah-Skhiri H, Traissac P, El Ati J, Eymard-Duvernay S, Landais E, et al. Nutrition transition among adolescents of a south-Mediterranean country: dietary patterns, association with socio-economic factors, overweight and blood pressure. A crosssectional study in Tunisia. Nutr J 2011;10:38.

30. Ghannem H, Fredj AH. Epidemiological transition and cardiovascular risk factors in Tunisia. Rev Epidemiol Sante Publique 1997;45:286-92.

31. Kelishadi R, Azizi Soleiman F. Controlling childhood obesity: a systematic review on strategies and challenges. J Res Med Sci 2014;19:993-1008.
32. Plachta-Danielzik S, Landsberg B, Lange D, Seiberl J, Müller MJ. Eight-year follow-up of school-based intervention on childhood overweight - The Kiel Obesity Prevention Study. Obes Facts 2011;4:35-43.

33. Muckelbauer R, Libuda L, Clausen K, Reinehr T, Kersting M. A simple dietary intervention in the school setting decreased incidence of overweight in children. Obes Facts 2009;2: 282-5.

34. Plachta-Danielzik S, Pust S, Asbeck I, Czerwinski-Mast M, Langnäse $\mathrm{K}$, et al. Four-year follow-up of school-based intervention on overweight children: the KOPS study. Obesity (Silver Spring) 2007;15:3159-69.

35. Gruber KJ, Haldeman LA. Using the family to combat childhood and adult obesity. Prev Chronic Dis 2009;6:A106.

36. Ball GD, Ambler KA, Keaschuk RA, Rosychuk RJ, Holt NL, et al. Parents as agents of change (PAC) in pediatric weight management: the protocol for the PAC randomized clinical trial. BMC Pediatr 2012;12:114.

37. Braden AL, Crow S, Boutelle K. Child self-reported motivations for weight loss: impact of personal vs. social/familial motives on family-based behavioral weight loss treatment outcomes. Eat Weight Disord 2015;20:205-13.

38. Maximova K, Ambler KA, Rudko JN, Chui N, Ball GDC. Ready, set, go! Motivation and lifestyle habits in parents of children referred for obesity management. Pediatr Obes 2014; DOI: 10.1111/ijpo.272 [Epub ahead of print].

39. Hall WJ, Schneider M, Thompson D, Volpe SL, Steckler A, et al. School factors as barriers to and facilitators of a preventive intervention for pediatric type 2 diabetes. Trans Behav Med 2014;4:131-40.

40. Ward DS, Saunders R, Felton GM, Williams E, Epping JN, et al. Implementation of a school environment intervention to increase physical activity in high school girls. Health Educ Res 2006;21:896-910.

41. Gittelsohn J, Merkle S, Story M, Stone EJ, Steckler A, et al. School climate and implementation of the Pathways study. Prev Med 2003;37:S97-106.

42. Goran MI, Reynolds K, Lindroos AK. Role of physical activity in the prevention of obesity in children. Int J Obes 1999;23:s18-33.

43. Kann L, Brener ND, Allensworth DD. Health education: results from the School Health Policies and Programs Study 2000. J Sch Health 2001;71:266-78.

44. Gibson CA, Smith BK, DuBose KD, Greene JL, Bailey BW, et al. Physical activity across the curriculum: year one process evaluation results. Int J Behav Nutr Phys Act 2008;5:1-11.

45. Donnelly JE, Greene JL, Gibson CA, Smith BK, Washburn RA, et al. Physical Activity Across the Curriculum (PAAC): a randomized controlled trial to promote physical activity and diminish overweight and obesity in elementary school children. Prev Med 2009;49:336-41.

46. Waters E, de Silva-Sanigorski A, Hall BJ, Brown T, Campbell KJ, et al. Interventions for preventing obesity in children. Cochrane Database Syst Rev 2011;12:CD001871. 